\title{
Predictive Factors of Survival in Patients Treated With Percutaneous Extracorporeal Membrane Oxygenation
}

\author{
Yasuhide Asaumi, MD, PhD; Manabu Matsumoto, MD; Satoshi Yasuda, MD, PhD
}

$\sqrt{ }$ enous-arterial percutaneous extracorporeal membrane oxygenation (V-A percutaneous extracorporeal membrane oxygenation (ECMO), also known as extracorporeal life support (ECLS), or especially in Japan, percutaneous cardiopulmonary support system (PCPS)) has been utilized in critical care medicine for patients with cardiogenic shock. ${ }^{1}$ For the very ill, ECMO is considered the first-line therapy because of its better cannulation techniques, improved oxygenation, device downsizing, and its rapid, easy, and less invasive application. ECMO is useful for patients with cardiogenic shock caused by fulminant myocarditis or acute coronary syndrome, as well as for patients who have undergone cardiopulmonary resuscitation (CPR). ${ }^{2-4}$ In the European Society of Cardiology guidelines on myocardial revascularization, ECMO implantation should be considered for temporary support of patients with acute heart failure with the potential for functional recovery following revascularization. ${ }^{5}$ The benefits of this technique's urgent application in acutely decompensated individuals outweigh its potential complications such as stroke, peripheral arterial ischemia, bleeding, and infections. The rate of survival following ECMO usage is reported to be $20-60 \%$. At the National Cerebral and Cardiovascular Center, 101 patients with refractory cardiogenic shock underwent ECMO over the past 20 years. Even recently, between 2005 and 2012, survival rates have been low: $21 \%$ for 29 patients with acute coronary syndrome (ACS), and $52 \%$ for 25 non-ACS patients, including those with fulminant myocarditis (Figure 1). ${ }^{6}$

\section{Article p 2064}

Regarding ECMO indications, it is often unclear whether the therapy should be used with patients who have undergone prolonged CPR or those who have experienced refractory cardiogenic shock, primarily because ECMO is very expensive once begun. ${ }^{7}$ We need to identify the factors predicting survival of patients with cardiogenic shock.

The APACHE (Acute Physiology, Age and Chronic Health Evaluation) study previously proposed a scoring system for such prediction. Acute kidney injury $48 \mathrm{~h}$ following ECMO support, renal replacement therapy, the existence of peripheral artery disease, and asystole or pulseless electrical activity before ECMO introduction predict worse survival following ECMO initiation. ${ }^{3,8-13}$ Acute myocarditis, high Glasgow Coma Scale score, and successful reperfusion therapy for ACS predict better survival (Figure 2). ${ }^{3,9,13}$

Shirakabe et al used initial findings at their emergency department to identify predictive factors for survival following V-A ECMO utilization. ${ }^{14}$ Their retrospective analysis revealed

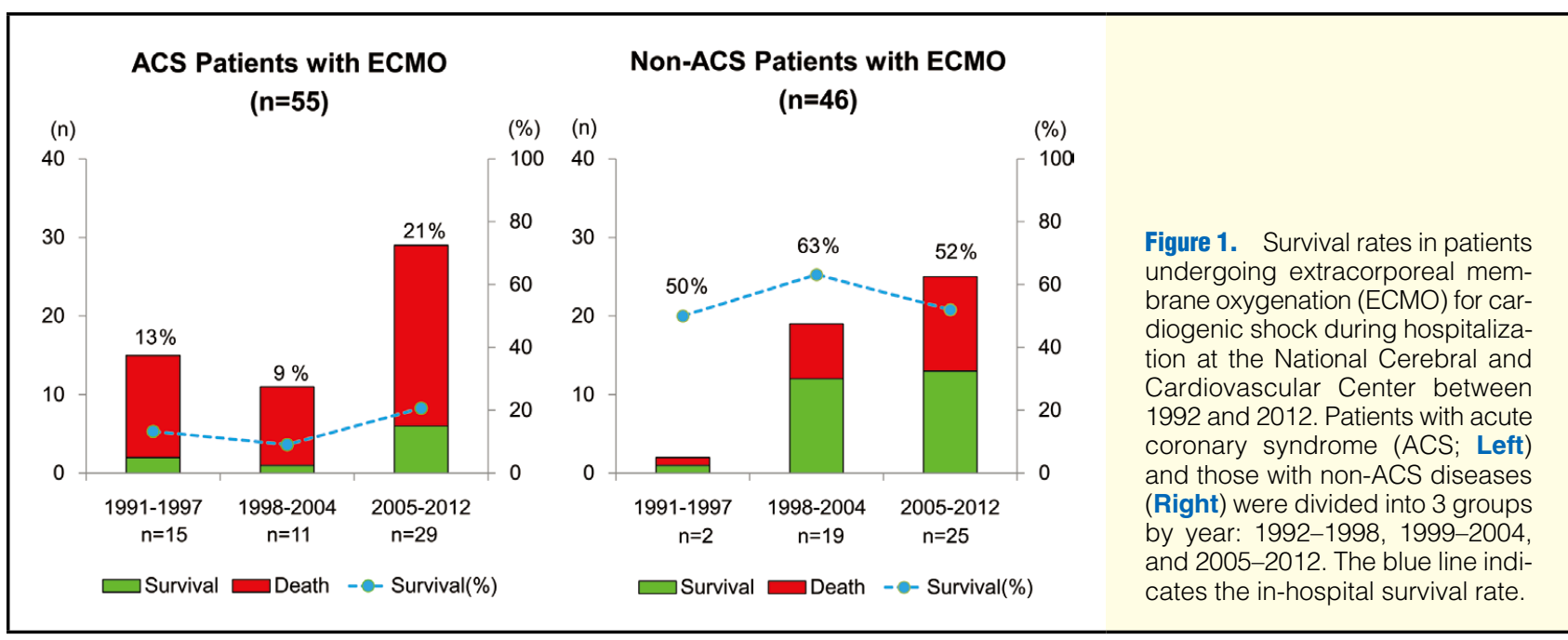

The opinions expressed in this article are not necessarily those of the editors or of the Japanese Circulation Society.

Received June 16, 2013; accepted June 17, 2013; released online July 5, 2013

Department of Cardiology, National Cerebral and Cardiovascular Center, Suita, Japan

Mailing address: Yasuhide Asaumi, MD, PhD, Department of Cardiology, National Cerebral and Cardiovascular Center, 5-7-1 Fujishiro-

dai, Suita 565-8565, Japan. E-mail: asaumi.yasuhide.hp@ncvc.go.jp

ISSN-1346-9843 doi:10.1253/circj.CJ-13-0765

All rights are reserved to the Japanese Circulation Society. For permissions, please e-mail: cj@j-circ.or.jp 


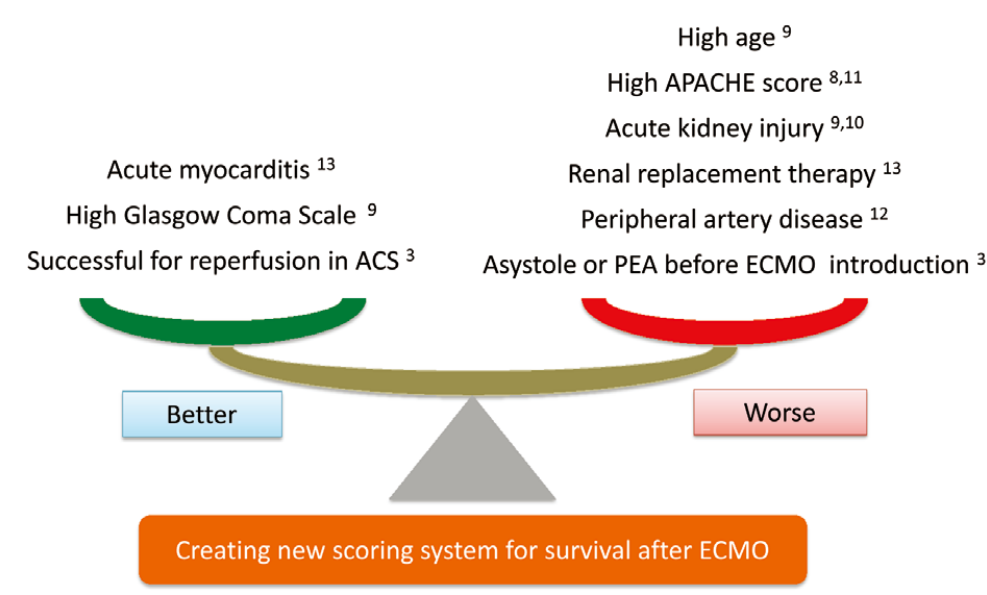

Figure 2. Predictors for survival in patients undergoing extracorporeal membrane oxygenation (ECMO) for cardiogenic shock. ACS, acute coronary syndrome; APACHE, Acute Physiology, Age and Chronic Health Evaluation; PEA, pulseless electrical activity.

that age under 50 years and starting ECMO within 45 min of the onset of shock were independent predictive factors for survival. By adding 3 other factors, including diagnosis of fulminant myocarditis, lack of out-of-hospital cardiac arrest, and ECMO attempted before cardiac arrest, the authors developed a scoring system that assigned 1 point for the occurrence of each of these 5 factors based on the patient's initial findings and history. ${ }^{14}$ For scores $\geq 2$, the sensitivity and specificity for survival following ECMO utilization were $85.7 \%$ and $66.7 \%$ (area under the curve, 0.781), respectively.

However, several unresolved questions remain. First, 3 patients survived despite having very low scores of 0 . Second, diagnosis of fulminant myocarditis was difficult in acute settings where available tools were limited. Third, although survival was used as the end point in this study, cerebral performance is also an important clinical goal.

The study by Shirakabe et al in this issue of the Journal is a first step in clarifying the predictive factors for weaning from and survival after percutaneous ECMO. The SAVE-J study (Study of Advanced life support for Ventricular fibrillation with Extracorporeal circulation in Japan), a prospective, observational, nationwide registry study for patients with cardiopulmonary arrest on arrival, has now been conducted. ${ }^{15}$ It is expected that the SAVE-J data will provide at least partial answers to our questions. Future research should include a multicenter, prospective registry study with a larger number of patients using ECMO for cardiogenic shock from all causes, including ACS and acute myocarditis.

\section{Disclosure}

None.

\section{References}

1. Kar B, Basra SS, Shah NR, Loyalka P. Percutaneous circulatory support in cardiogenic shock: Interventional bridge to recovery. Circulation 2012; 125: 1809-1817.

2. Asaumi Y, Yasuda S, Morii I, Kakuchi H, Otsuka Y, Kawamura A, et al. Favourable clinical outcome in patients with cardiogenic shock due to fulminant myocarditis supported by percutaneous extracorporeal membrane oxygenation. Eur Heart J 2005; 26: 2185-2192.

3. Sakamoto S, Taniguchi N, Nakajima S, Takahashi A. Extracorporeal life support for cardiogenic shock or cardiac arrest due to acute coronary syndrome. Ann Thorac Surg 2012; 94: 1-7.
4. Chen YS, Chao A, Yu HY, Ko WJ, Wu IH, Chen RJ, et al. Analysis and results of prolonged resuscitation in cardiac arrest patients rescued by extracorporeal membrane oxygenation. J Am Coll Cardiol 2003; 41: 197-203.

5. Wijns W, Kolh P, Danchin N, Di Mario C, Falk V, Folliguet T, et al. Guidelines on myocardial revascularization. Task Force on Myocardial Revascularization of the European Society of Cardiology (ESC) and the European Association for Cardio-Thoracic Surgery (EACTS); European Association for Percutaneous Cardiovascular Interventions (EAPCI). Eur Heart J 2010; 31: 2501 - 2555.

6. Matsumoto M, Yasuda S, Yamane T, Adachi T, Miyagi T, Nagai T, et al. Over 20-years trend of in-hospital mortality in patients with cardiogenic shock using percutaneous extracorporeal membrane oxygenation: Comparison between ACS and non ACS patients. J Am Coll Cardiol 2012; 61: E18, doi:10.1016/S0735-1097(13)60019-4.

7. Peek GJ, Mugford M, Tiruvoipati R, Wilson A, Allen E, Thalanany $\mathrm{MM}$, et al. Efficacy and economic assessment of conventional ventilatory support versus extracorporeal membrane oxygenation for severe adult respiratory failure (CESAR): A multicentre randomised controlled trial. Lancet 2009; 374: 1351-1363

8. Lin CY, Tsai FC, Tian YC, Jenq CC, Chen YC, Fang JT, et al. Evaluation of outcome scoring systems for patients on extracorporeal membrane oxygenation. Ann Thorac Surg 2007; 84: 1256-1262.

9. Chen YC, Tsai FC, Chang CH, Lin CY, Jenq CC, Juan KC, et al. Prognosis of patients on extracorporeal membrane oxygenation: The impact of acute kidney injury on mortality. Ann Thorac Surg 2011; 91: $137-142$.

10. Chang WW, Tsai FC, Tsai TY, Chang CH, Jenq CC, Chang MY, et al. Predictors of mortality in patients successfully weaned from extracorporeal membrane oxygenation. PLoS One 2012; 7: e42687, doi:10.1371/journal.pone.0042687.

11. Chung SY, Sheu JJ, Lin YJ, Sun CK, Chang LT, Chen YL, et al. Outcome of patients with profound cardiogenic shock after cardiopulmonary resuscitation and prompt extracorporeal membrane oxygenation support: A single-center observational study. Circ J 2012; 76:1385-1392.

12. Bisdas T, Beutel G, Warnecke G, Hoeper MM, Kuehn C, Haverich A, et al. Vascular complications in patients undergoing femoral cannulation for extracorporeal membrane oxygenation support. Ann Thorac Surg 2011; 92: 626-631.

13. Thiagarajan RR, Brogan TV, Scheurer MA, Laussen PC, Rycus PT, Bratton SL. Extracorporeal membrane oxygenation to support cardiopulmonary resuscitation in adults. Ann Thorac Surg 2009; 87: $778-785$.

14. Shirakabe A, Nozaki A, Hata N, Kobayashi N, Shinada T, Tomita K, et al. Predictive score for survival after percutaneous cardiopulmonary support in cardiovascular disease patients. Circ J 2013; 77: $2064-2072$.

15. Morimura N, Sakamoto T, Nagao K, Asai Y, Yokota H, Tahara Y, et al. Extracorporeal cardiopulmonary resuscitation for out-of-hospital cardiac arrest: A review of the Japanese literature. Resuscitation 2011; 82: 10-14. 